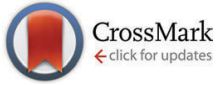

Cite this: J. Mater. Chem. C, 2015 , 3, 3569

Received 26th January 2015, Accepted 25th February 2015

DOI: $10.1039 / c 5 t c 00253 b$

www.rsc.org/MaterialsC

\title{
Air-stable $\mathrm{n}$-channel organic field-effect transistors based on a sulfur rich $\pi$-electron acceptor
}

\author{
Agathe Filatre-Furcate, ${ }^{\star a b}$ Toshiki Higashino, ${ }^{{ }^{a}}$ Dominique Lorcy $^{\mathrm{b}}$ and \\ Takehiko Mori ${ }^{\mathrm{a}}$
}

\begin{abstract}
Thin-film and single-crystal $\mathrm{n}$-channel organic field-effect transistors are built from the sulfur rich $\pi$-electron acceptor, (E)-3,3'-diethyl-5,5'-bithiazolidinylidene-2,4,2',4'-tetrathione (DEBTTT). Different source and drain electrode materials are investigated: gold, the conducting charge transfer salt (tetrathiafulvalene)(tetracyanoquinodimethane), and carbon paste. Regardless of the nature of the electrodes, air-stable $\mathrm{n}$-channel transistors have been obtained. Single crystals exhibit a higher performance than the thin-film transistors with a mobility of up to $0.22 \mathrm{~cm}^{2} \mathrm{~V}^{-1} \mathrm{~s}^{-1}$. These thin-film and single-crystal devices exhibit excellent long-term stability as demonstrated by the mobility measured during several weeks. The high mobility and air stability are ascribed to the characteristic three-dimensional S-S network coming from the thioketone sulfur atoms.
\end{abstract}

\section{Introduction}

Over the last few decades, organic field-effect transistors (OFETs) have attracted a lot of attention owing to their potential application to flexible, and low-cost electronic devices. ${ }^{1-3}$ For that purpose, a variety of p-channel and n-channel organic semiconductors have been studied and over the years a significantly improved performance has been obtained. ${ }^{2,3}$ Among these OFETs, despite the increasing number of related studies, n-channel organic semiconductors have been less investigated than p-channel organic semiconductors. ${ }^{4-12}$ Thus, air-stable n-channel transistors exhibiting high electronic performance are rare in comparison with p-channel devices. To prepare air-stable n-channel organic transistors, a strategy is the use of electron acceptors with the lowest unoccupied molecular orbital (LUMO) energy lower than $-4.0 \mathrm{eV} .{ }^{12}$ For instance, small molecules such as TCNQ $(7,7,8,8-$ tetracyano-p-quinodimethane) and DM-DCNQI (2,5-dimethyl$N, N^{\prime}$-dicyano-p-quinonediimine), which are both planar and strong electron acceptors, give air-stable n-channel thin-film OFETs. ${ }^{7-9}$

\footnotetext{
${ }^{a}$ Department of Organic and Polymeric Materials, Tokyo Institute of Technology, O-okayama 2-12-1, Meguro-ku, 152-8552, Japan.

E-mail: higashino.t.aa@m.titech.ac.jp, mori.t.ae@m.titech.ac.jp

${ }^{b}$ Institut des Sciences Chimiques de Rennes, Université de Rennes 1, CNRS UMR 6226, Matière Condensée et Systèmes Electroactifs (MaCSE), campus de Beaulieu, Bât 10A, 35042 Rennes cedex, France.

E-mail: agathe.filatre-furcate@univ-rennes1.fr

$\dagger$ Electronic supplementary information (ESI) available: Additional information for overlap integral calculations, optical properties, device fabrication, and thin film properties. See DOI: $10.1039 / \mathrm{c} 5$ tc00253b
}

Moreover, single crystals of TCNQ afford higher-performance n-channel devices than the thin-film transistors. ${ }^{7,8}$ The introduction of chalcogen atoms such as sulfur within the acceptor skeleton is another structural feature which leads to highperformance and air-stable n-channel OFETs. ${ }^{5}$ In fact, it is well known that the presence of sulfur atoms can enhance intermolecular interactions due to sulfur $\cdots$ sulfur contacts and thus can increase the effective dimensionality of the electronic structure and consequently the transport properties. ${ }^{13}$ Therefore, it is interesting to explore this category of molecules as candidates of new electron-transporting organic semiconductors. We have recently reported a sulfur-rich electron acceptor, $(E)$-3, $3^{\prime}$-diethyl$5,5^{\prime}$-bithiazolidinylidene-2, $4,2^{\prime}, 4^{\prime}$-tetrathione (DEBTTT); due to its electron accepting ability, $\left(E_{1}^{1 / 2}=-0.05 \mathrm{~V}\right.$ and $E_{2}^{1 / 2}=-0.44 \mathrm{~V} v s$. SCE), this acceptor forms a charge-transfer salt with decamethylferrocene exhibiting ferromagnetic interaction. ${ }^{14}$ This molecule was first obtained as a side product of nickel dithiolene complexes ${ }^{15}$ and it can be simply prepared from the oxidation of the dithiolate ligand. ${ }^{14}$ The monoketone form of the half unit of this acceptor is known as 3-ethyl rhodanine, which is included in dyes such as merocyanine, and used in the prototypical OFET and organic photovoltaic cell. ${ }^{16,17}$ The DEBTTT molecule with its six sulfur atoms exhibits a planar geometry in its neutral and monoanionic states and undergoes two sequential and reversible monoelectronic reduction processes at less anodic potential than $\operatorname{TCNQ}\left(E_{1}^{1 / 2}=0.18 \mathrm{~V}\right.$ and $E_{2}^{1 / 2}=-0.37 \mathrm{~V} v$ s. SCE $),{ }^{18}$ demonstrating a slightly lower accepting ability than TCNQ. From redox potential analysis, the LUMO energy of DEBTTT was estimated to be $-4.4 \mathrm{eV}$, which is within the region of air-stable electron transport. ${ }^{19}$ 
Thus, DEBTTT presents favorable prerequisites for the elaboration of air-stable n-channel OFETs. ${ }^{12}$<smiles>CCN1C(=S)S/C(=C2\SC(=S)N(CC)C2=S)C1=S</smiles>

In this paper, we report the characteristics of DEBTTT thin-films and single-crystal n-channel OFETs, using different source and drain electrode materials such as gold, the conducting charge transfer salt (tetrathiafulvalene)(tetracyanoquinodimethane) ((TTF)(TCNQ)), and carbon paste. These transistors show excellent air and longterm stability owing to the fairly strong acceptor ability.

\section{Results and discussion}

\section{Fabrication of devices}

Thin films of DEBTTT have been deposited by vacuum evaporation on a tetratetracontane (TTC)-modified $\mathrm{SiO}_{2} / \mathrm{Si}$ substrate; TTC behaves as an excellent passivation layer. ${ }^{20,21}$ The top-contact source and drain electrodes are fabricated by evaporating gold or (TTF)(TCNQ) through a shadow mask leading to a channel of $100 \mu \mathrm{m}$ length and $1 \mathrm{~mm}$ width. Concerning the top-contact single crystal devices, polystyrene (PS) was used as a passivation layer and carbon paste as a source-drain electrode. The transistor characteristics were measured under vacuum $\left(10^{-4} \mathrm{~Pa}\right)$ and under an ambient atmosphere (see ESI $\dagger$ for details). The mobility was evaluated in the saturated region.

\section{Thin film properties}

The solid state morphology and crystallinity of the thin films have been investigated by ultraviolet-visible spectroscopy (UV/vis) $(\mathrm{ESI} \dagger)$, X-ray diffraction (XRD), and atomic force microscopy (AFM). The XRD pattern, (Fig. 1a), shows diffraction peaks which can be attributed to the polycrystalline passivation layer as well as to the organic semiconducting film (peak at $d=11.6 \AA$ ). Based on the crystal structure, ${ }^{14}$ this $d$-spacing, at $d=11.6 \AA$, corresponds to the $c \sin \alpha \sin \beta$ distance of the crystal lattice, indicating that the crystallographic $a b$ plane is aligned parallel to the substrate as shown in Fig. 1b. The molecules are almost perpendicular to the substrate (tilt angles: $85.5^{\circ}$ and $88.4^{\circ}$ ). (a)

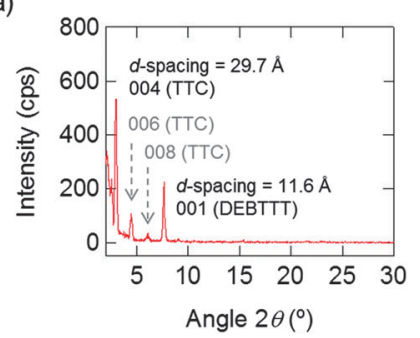

(b)

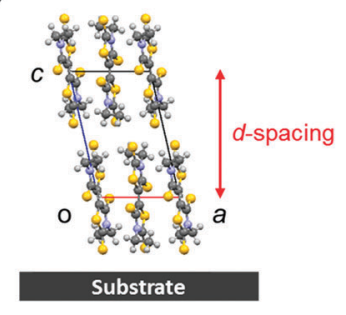

Fig. 1 (a) X-ray diffraction pattern, and (b) the molecular arrangement of DEBTTT on the substrate.
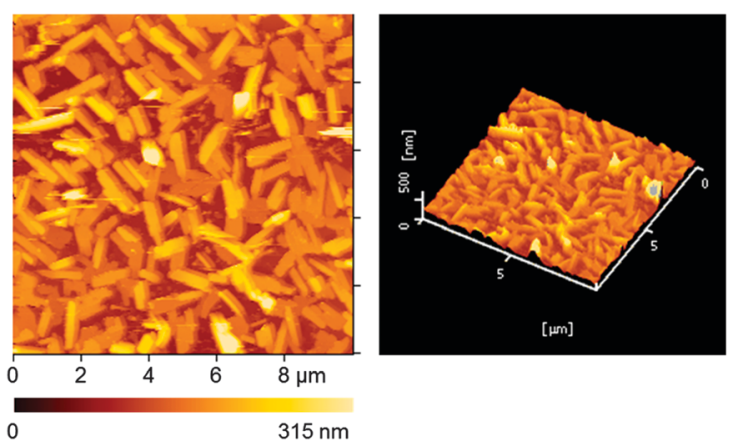

Fig. 2 AFM topographical image of $50 \mathrm{~nm}$ thin films of DEBTTT deposited on TTC.

Accordingly, the stacking direction of the molecules is almost parallel to the substrate which is generally favorable for charge transport in transistors. Indeed, it has been reported in a naphthalene diimide series that there is a correlation between mobility and molecular arrangement and that the perpendicular orientation is the most favorable for charge transport in organic transistors as it minimizes the misfit between the domain boundaries. $^{22}$ The low-angle peaks come from the passivation layer. TTC is known to show five different packing modes: monoclinic $\left(\mathbf{M}_{001}\right.$ and $\left.\mathrm{M}_{101}\right)$, triclinic $(\mathrm{T})$, orthorhombic $\mathrm{I}\left(\mathrm{O}_{\mathrm{I}}\right)$ and orthorhombic II $\left(\mathrm{O}_{\text {II }}\right)$ systems. $^{23}$ The observed XRD peaks are ascribed to the orthorhombic I $\left(\mathrm{O}_{\mathrm{I}}\right)$ system, where the TTC molecules stand perpendicular to the $\mathrm{SiO}_{2}$ surface.

AFM images of the evaporated thin films of DEBTTT (Fig. 2) show homogeneous microcrystalline features. This crystallinity could be due to the ability of DEBTTT to establish strong intramolecular and intermolecular interactions ${ }^{14}$ and to the influence of the TTC passivation layer because it has been previously reported that the crystallinity of a wide variety of organic semiconductors increases when deposited on TTC..$^{20,21}$

\section{Intermolecular interactions}

Overlap integral calculations have been performed in order to determine the strength of the interactions between neighbouring molecules in the solid state. The transfer integrals (Fig. 3) for the adjacent molecules between the $\pi$-type LUMOs ${ }^{14}$ are determined based on AM1 molecular orbital calculations (see ESI $\dagger$ ). ${ }^{24}$

The transfer integral $a$ along the column is significantly smaller than those for the diagonal interactions $b 1, b 2$ and $p$ between the adjacent columns within the $a b$ plane. It finds its origin in the steric effect of the ethyl group which induces a rotation of the molecules relative to each other in the stack (Fig. 3c), and reduces the intracolumnar interactions. Another reason for this small intracolumnar interaction is the nature of the LUMO which is not largely populated on the ring sulfur atoms. Contrariwise, there are significant contributions in the LUMO on the four exocyclic sulfur atoms involved in short S $\cdots S$ contacts associated with these strong diagonal interactions $b 1$, $b 2$ and $p$. As shown in Fig. 3c, the thioketone sulfur atoms afford many $S \cdots S$ contacts shorter than the van der Waals distance not only in the stacking direction but also in the other two ( $b$ and $c$ ) directions. It is noteworthy that this compound does 


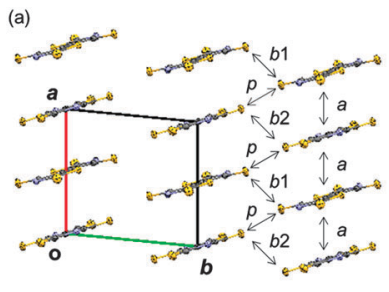

(b)
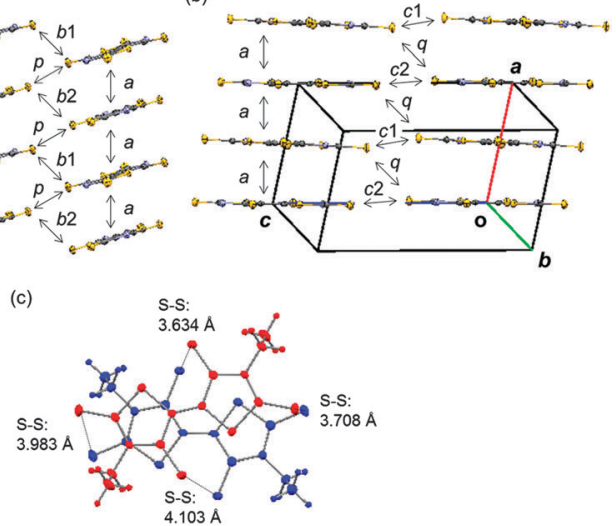

Fig. 3 Crystal structures of DEBTTT, viewed along (a) the $c$ axis and (b) the molecular short axis (ethyl groups are omitted for clarity). (c) Overlap mode in the stack. Transfer integrals of the LUMO-LUMO interactions: $a=-4.1$, $b 1=-18.5, b 2=-74.5, c 1=8.8, c 2=0.3, p=-12.0$, and $q=-8.6 \mathrm{meV}$. S-S distances: $a$ shown in (c), $b 1=3.841, b 2=3.451, c 1=3.341, c 2=$ 4.683, $p=3.452$, and $q=4.159 \AA$.

not show a simple one-dimensional intermolecular interaction coming from the $\pi$-stacks. The three-dimensional interactions mediated by the thioketone $\mathrm{S} \cdots \mathrm{S}$ contacts are responsible for the highly crystalline nature and the robust electron transport.

\section{Transistor characteristics}

Transfer and output characteristics of the thin film and single crystal transistors are, respectively, shown in Fig. 4 and 5. From these characteristics, the maximum and average of the apparent mobilities, $\mu_{\max }$ and $\mu_{\mathrm{av}}$, are estimated as well as the on-off ratio $I_{\mathrm{ON}} / I_{\mathrm{OFF}}$ and the threshold voltage $V_{\mathrm{Th}}$. The device performances are summarized in Table 1. Among the thin-film transistors, the transistors using (TTF)(TCNQ) electrodes exhibit higher performances than those with the gold electrodes (Table 1). The high temperature used for evaporating gold electrodes $\left(T>500{ }^{\circ} \mathrm{C}\right)$ is
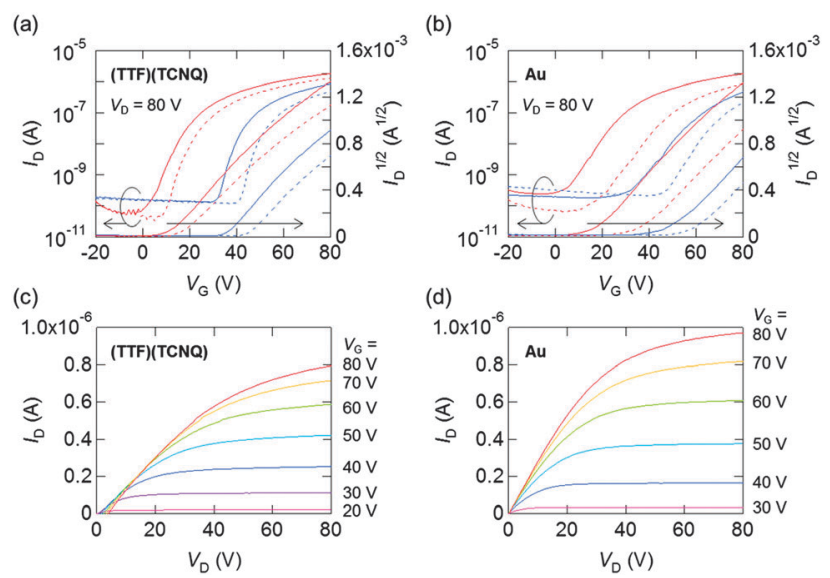

Fig. $4 \mathrm{~N}$-channel characteristics of thin-film transistors based on DEBTTT. Transfer characteristics measured under vacuum (solid curves) and in air (dotted curves) with (a) (TTF)(TCNQ) and (b) Au electrodes: pristine (red) and after ten weeks (blue). Output characteristics measured under vacuum with (c) (TTF)(TCNQ) and (d) Au electrodes.
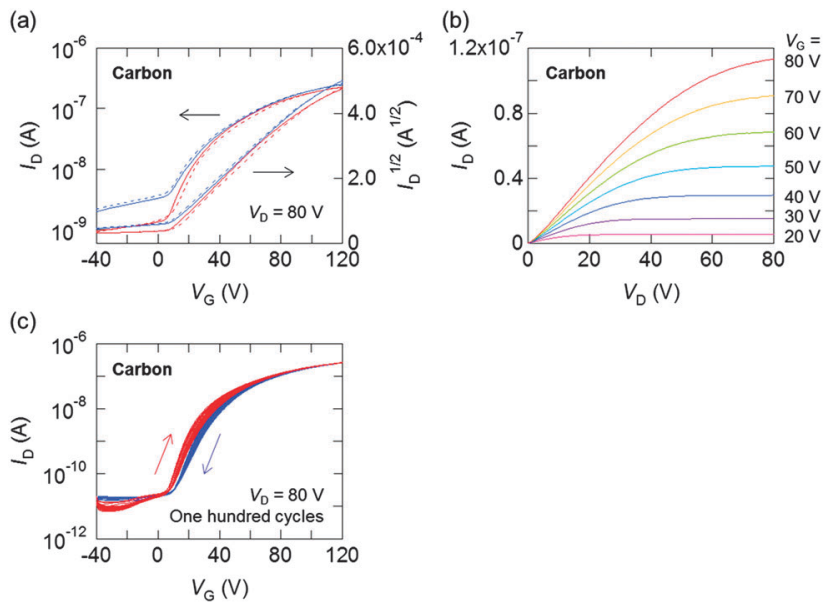

Fig. $5 \mathrm{~N}$-channel characteristics of single-crystal transistors based on DEBTTT with carbon electrodes. (a) Transfer characteristics measured under vacuum (solid curves) and in air (dotted curves). The measurements just after the fabrication (red) and after six weeks (blue). (b) Output characteristics measured under vacuum. (c) One-hundred cycles of transfer curves measured in air.

known to generate slight damage on the organic semiconductor film in some cases. The better performance of the (TTF)(TCNQ) transistors is partially due to the comparatively low-temperature evaporation of the (TTF)(TCNQ) electrodes $\left(130{ }^{\circ} \mathrm{C}\right)$. The differences in the electrode work function also influence the performance of the devices (see below). The transistors are operated even in air and the performance is not much reduced (Table 1). The (TTF)(TCNQ)-based transistors tend to afford smaller $V_{\mathrm{Th}}$ than the Au-based transistors.

Moreover, the transistors based on single crystals of DEBTTT exhibit higher performance than the thin-film devices with a mobility of up to $0.22 \mathrm{~cm}^{2} \mathrm{~V}^{-1} \mathrm{~s}^{-1}$ (Fig. 5 and Table 1). The single crystal device also achieves a good performance and low threshold voltage even in air. These results are due to the fact that with crystals, complications resulting from grain boundaries and film morphology are excluded. In addition, the three-dimensional S-S network is expected to block the attack of gaseous water and oxygen, and is related to the extreme robustness of the electron transport against air.

After several-week storage, the mobilities of the thin-film transistors are practically not changed (Table 1), though the threshold voltages are shifted (Fig. 4). In the single-crystal transistors, the threshold shift is very small (Fig. 5), and the average mobility is not modified. In addition, we have carried out one hundred cycles of measurements in air and the performance is practically unchanged (Fig. 5c and Fig. S3, ESI $\dagger$ ). Thus these n-channel transistors exhibit excellent long-term stability.

When we investigate the energy levels of the acceptor and the electrode materials, considerable difference exists between the electron affinity of the acceptor $(4.4 \mathrm{eV})$ and the gold work function (5.1 eV) (Fig. 6). ${ }^{25}$ By contrast, the Fermi level of (TTF)(TCNQ) is located more close to the acceptor energy level, because the (TTF)(TCNQ) energy level is located in between the highest occupied molecular orbital level of TTF $(4.78 \mathrm{eV})$ and the lowest unoccupied molecular orbital level of TCNQ (4.62 eV). ${ }^{26-29}$ 
Table 1 Maximum mobility $\left(\mu_{\text {max }}\right)$, average mobility $\left(\mu_{\mathrm{av}}\right)$, threshold voltage $\left(V_{\mathrm{Th}}\right)$ and on/off ratio $\left(I_{\mathrm{ON}} / /_{\mathrm{OFF}}\right)$ of the transistors based on DEBTTT under vacuum and ambient conditions

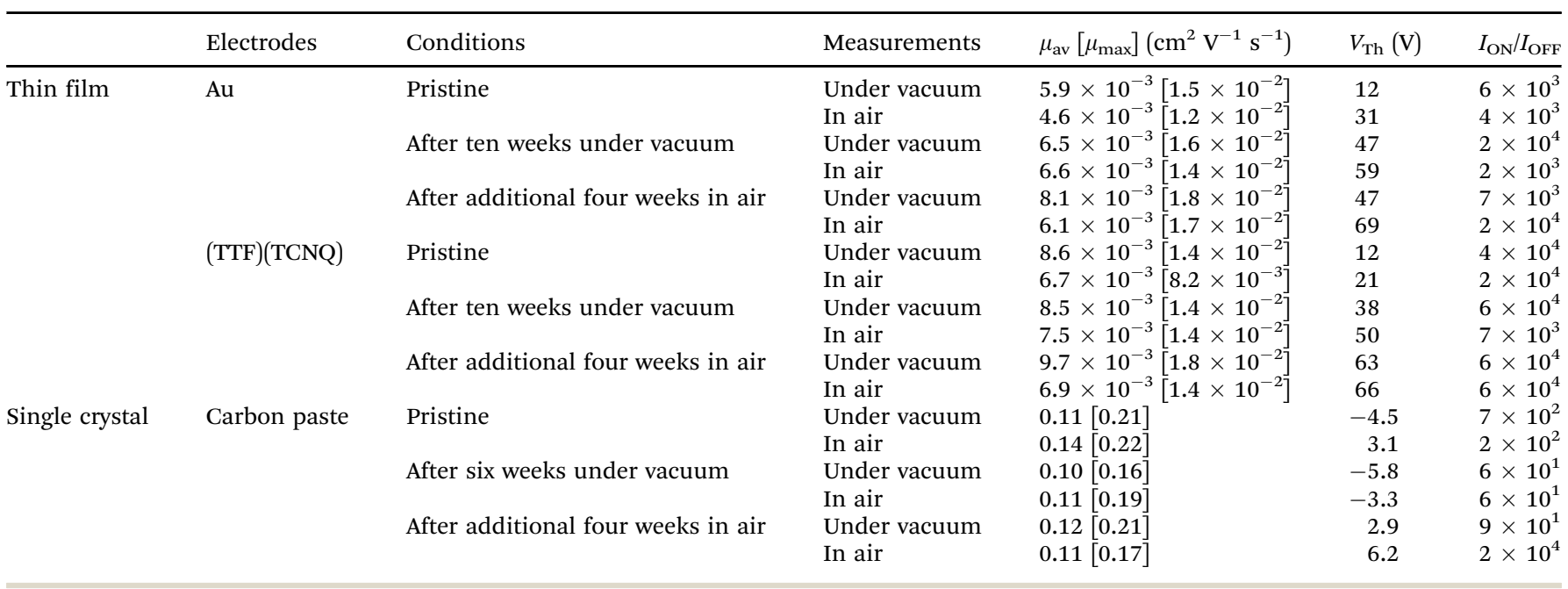

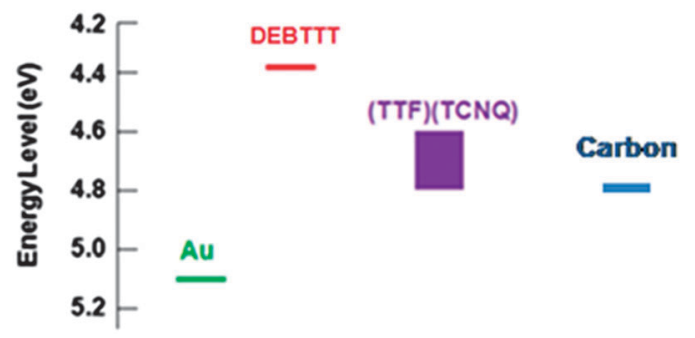

Fig. 6 Energy levels of DEBTTT and the related materials.

The resulting reduced Schottky barrier is another origin of the better performance of the (TTF)(TCNQ)-based transistors. In addition, the Fermi level of carbon $(4.8 \mathrm{eV})$ indicates that carbon is also a good candidate of source-drain electrodes in high-performance n-channel transistors based on DEBTTT. ${ }^{30}$

\section{Conclusions}

In conclusion, we have investigated organic transistors based on DEBTTT. It is noticed that the transistors show sufficiently stable performance even in air. A higher performance has been obtained for (TTF)(TCNQ) electrodes than for the ordinary gold ones, partly owing to the reduction of the heat damage in the electrode evaporation process. The thin-film transistor of DEBTTT shows a better performance than the TCNQ-based thin-film transistors. ${ }^{5 a}$ In particular, the single-crystal transistors exhibit mobility as high as $0.22 \mathrm{~cm}^{2} \mathrm{~V}^{-1} \mathrm{~s}^{-1}$. In contrast to the ordinary organic transistors which exhibit a highly two-dimensional layered structure, the extensive three-dimensional S-S interactions are characteristics of the present material. This may be related to the extensive air stability of this material.

\section{Acknowledgements}

We thank Rennes Métropole and the Agence Nationale de la Recherche, France (ANR project no. 12-BS07-0032) for financial support to AFF internship. The authors are grateful to Tokyo Institute of Technology Center for Advanced Materials Analysis for XRD measurement and Prof. Kakimoto for AFM measurements. This work was partly supported by a Grant-in Aid for Scientific Research (B) (no. 23350061) from the Ministry of Education, Culture, Sports, Science, and Technology of Japan.

\section{Notes and references}

1 (a) C. D. Dimitrakopoulos and P. R. L. Malenfant, $A d v$. Mater., 2002, 14, 99; (b) Z. Bao and J. Locklin, Organic Field-Effect Transistors, CRC Press, New-York, 2007.

2 C. Wang, H. Dong, W. Hu, Y. Liu and D. Zhu, Chem. Rev., 2012, 112, 2208.

3 A. R. Murphy and J. M. J. Fréchet, Chem. Rev., 2007, 107, 1066.

4 C. R. Newman, C. D. Frisbie, D. A. da Silva Filho, J.-L. Brédas, P. C. Ewbank and K. R. Mann, Chem. Mater., 2004, 16, 4436.

5 (a) Y. Wen and Y. Liu, Adv. Mater., 2010, 22, 1331; (b) Y. Yamashita, Chem. Lett., 2009, 38, 870; (c) Y. Qiao, Y. Guo, C. Yu, F. Zhang, W. Xu, Y. Liu and D. Zhu, J. Am. Chem. Soc., 2012, 134, 4084; (d) X. Gao, C. Di, Y. Hu, X. Yang, H. Fan, F. Zhang, Y. Liu, H. Li and D. Zhu, J. Am. Chem. Soc., 2010, 132, 3697; (e) Y. Hu, X. Gao, C. Di, X. Yang, F. Zhang, Y. Liu, H. Li and D. Zhu, Chem. Mater., 2011, 23, 1204; $(f)$ L. Tan, Y. Guo, G. Zhang, Y. Yang, D. Zhang, G. Yu, W. Xu and Y. Liu, J. Mater. Chem., 2011, 21, 18042; (g) F. Zhang, Y. Hu, T. Schuettfort, C. Di, X. Gao, C. R. McNeill, L. Thomsen, S. C. B. Mannsfeld, W. Yuan, H. Sirringhaus and D. Zhu, J. Am. Chem. Soc., 2013, 135, 2338; (h) X. Gao and Y. Hu, J. Mater. Chem. C, 2014, 2, 3099.

6 T. Mori, Chem. Lett., 2011, 40, 428.

7 (a) E. Menard, V. Podzorov, S.-H. Hur, A. Gaur, M. E. Gershenson and J. A. Rogers, Adv. Mater., 2004, 16, 2097; (b) A. R. Brown, D. M. de Leeuw, E. J. Lous and E. E. Havinga, Synth. Met., 1994, 66, 257; (c) M. Yamagishi, Y. Tominari, T. Uemura and J. Takeya, Appl. Phys. Lett., 2009, 94, 053305. 
8 T. Takahashi, S. Tamura, Y. Akiyama, T. Kadoya, T. Kawamoto and T. Mori, Appl. Phys. Express, 2012, 5, 061601.

9 H. Wada, K. Shibata, Y. Bando and T. Mori, J. Mater. Chem., 2008, 18, 4165.

10 D. de Caro, K. Jacob, H. Hahioui, C. Faulmann, L. Valade, T. Kadoya, T. Mori, J. Fraxedas and L. Viau, New J. Chem., 2011, 35, 1315.

11 (a) S. Handa, E. Miyazaki, K. Takimiya and Y. Kunugi, J. Am. Chem. Soc., 2007, 129, 11684; (b) Z. Liang, Q. Tang, J. Xu and Q. Miao, Adv. Mater., 2011, 23, 1535; (c) A. Lv, S. R. Puniredd, J. Zhang, Z. Li, H. Zhu, W. Jiang, H. Dong, Y. He, L. Jiang, Y. Li, W. Pisula, Q. Meng, W. Hu and Z. Wang, Adv. Mater., 2012, 24, 2626; (d) T. Kono, D. Kumaki, J. Nishida, S. Tokito and Y. Yamashita, Chem. Commun., 2010, 46, 3265; (e) D. Song, H. Wang, F. Zhu, J. Yang, H. Tian, Y. Geng and D. Yan, Adv. Mater., 2008, 20, 2142.

12 H. Usta, A. Facchetti and T. J. Marks, Acc. Chem. Res., 2011, 44, 501.

13 W. Jiang, Y. Li and Z. Wang, Chem. Soc. Rev., 2013, 42, 6113. 14 Y. Le Gal, N. Bellec, F. Barrière, R. Clérac, M. Fourmigué, V. Dorcet, T. Roisnel and D. Lorcy, Dalton Trans., 2013, 42, 16672.

15 M. C. Aragoni, M. Arca, F. A. Devillanova, F. Isaia, V. Lippolis, A. Mancini, L. Pala, A. M. Z. Slawin and J. D. Woolins, Inorg. Chem., 2005, 44, 9610.

16 K. Kudo, M. Yamashita and T. Moriizumi, Jpn. J. Appl. Phys., 1984, 23, 130.

17 D. L. Morel, E. L. Stogryn, A. K. Ghosh, T. Feng, P. E. Purwin, R. F. Shaw, C. Fishman, G. R. Bird and A. P. Piechowski, J. Phys. Chem., 1984, 88, 923.

18 M. L. Kaplan, R. C. Haddon, F. B. Bramwell, F. Wudl, J. H. Marshall, D. O. Cowan and S. Gronowitz, J. Phys. Chem., 1980, 84, 427.

19 M. L. Tang, A. D. Reicharrdt, P. Wei and Z. Bao, J. Am. Chem. Soc., 2009, 131, 5264.

20 (a) M. Kraus, S. Richler, A. Opitz, W. Brütting, S. Haas, T. Hasegawa, A. Hinderhofer and F. Schreiber, J. Appl. Phys., 2010, 107, 094503; (b) M. Kraus, S. Haug, W. Brütting and A. Opitz, Org. Electron., 2011, 12, 731.

21 (a) A. Opitz, M. Horlet, M. Kiwull, J. Wagner, M. Kraus and W. Brütting, Org. Electron., 2012, 13, 1614; (b) M. Irimia-Vladu, E. D. Głowacki, P. A. Troshin, G. Schwabegger, L. Leonat, D. K. Susarova, O. Krystal, M. Ullah, Y. Kanbur, M. A. Bodea, V. F. Razumov, H. Sitter, S. Bauer and N. S. Sariciftci, Adv. Mater., 2012, 24, 375;

(c) E. D. Głowacki, L. Leonat, G. Voss, M.-A. Bodea, Z. Bozkurt, A. M. Ramil, M. Irimia-Vladu, S. Bauer and N. S. Sariciftci, AIP Adv., 2011, 1, 042132; (d) E. D. Głowacki, G. Voss, L. Leonat, M. Irimia-Vladu, S. Bauer and N. S. Sariciftci, Isr. J. Chem., 2012, 52, 540; (e) E. D. Głowacki, D. H. Apaydin, Z. Bozkurt, U. Monkowius, K. Demirak, E. Tordin, M. Himmelsbach, C. Schwarzinger, M. Burian, R. T. Lechner, N. Demitri, G. Vossa and N. S. Sariciftci, J. Mater. Chem. C, 2014, 2, 8089; $(f)$ O. Pitayatanakul, T. Higashino, T. Kadoya, M. Tanaka, H. Kojima, M. Ashizawa, T. Kawamoto, H. Matsumoto, K. Ishikawa and T. Mori, J. Mater. Chem. C, 2014, 2, 9311; (g) E. D. Głowacki, H. Coskun, M. A. Blood-Forsythe, U. Monkowius, L. Leonat, M. Grzybowski, D. Gryko, M. S. White, A. Aspuru-Guzik and N. S. Sariciftci, Org. Electron., 2014, 15, 3521.

22 T. Kakinuma, H. Kojima, M. Ashizawa, H. Matsumoto and T. Mori, J. Mater. Chem. C, 2013, 1, 5395.

23 J.-P. Gorce, S. J. Spells, X.-B. Zeng and G. Ungar, J. Phys. Chem. B, 2004, 108, 3130.

24 (a) M. J. S. Dewar, E. G. Zoebisch, E. F. Healy and J. J. P. Stewart, J. Am. Chem. Soc., 1985, 107, 3902; (b) T. Mori, A. Kobayashi, Y. Sasaki, H. Kobayashi, G. Saito and H. Inokuchi, Bull. Chem. Soc. Jpn., 1984, 57, 627.

25 H. Michelson, IBM J. Res. Dev., 1978, 22, 72.

26 T. Kadoya, D. de Caro, K. Jacob, C. Faulmann, L. Valade and T. Mori, J. Mater. Chem., 2011, 21, 18421.

27 A. S. Batsanov, M. R. Bryce, A. Chesney, J. A. K. Howard, D. E. John, A. J. Moore, C. L. Wood, H. Gershtenman, J. Y. Becker, V. Y. Khodorkovsky, A. Ellern, J. Bernstein, I. F. Perepichka, V. Rotello, M. Gray and A. O. Cuello, J. Mater. Chem., 2001, 11, 2181.

28 Y. Takahashi, T. Hasegawa, Y. Abe, Y. Tokura and G. Saito, Appl. Phys. Lett., 2006, 88, 073504.

29 S. Tamura, T. Kadoya, T. Kawamoto and T. Mori, Appl. Phys. Lett., 2013, 102, 063305.

30 M. Shiraishi and M. Ata, Carbon, 2001, 39, 1913. 